\title{
Usefulness of a regional probabilistic approach to determining design discharges of hydropower plants in Albania
}

\author{
Jean-Claude Carré ${ }^{1, a}$, Stéphanie Diss ${ }^{1}$ and Luc Hamm ${ }^{1}$ \\ ${ }^{1}$ ARTELIA, 6 rue de Lorraine, 38130 Echirolles, France
}

\begin{abstract}
This paper presents the results obtained using the PARDES-flood method in Albania to determine discharges of hydropower plants. The first part of the method is a regional probabilistic approach to extreme rainfall. The second part is related to the determination of extreme maximum peak discharges thanks to two probabilistic relations between statistical quantiles. The original approach in the first part lies in combining the probabilistic theory of Poisson's process, regional analysis and the integration of particular phenomena linked to orographic features. The rivers studied in Albania include the Vjosa, which flows through the southern part of the country. It has a total length of $272 \mathrm{~km}, 80 \mathrm{~km}$ of which are in Greece. In this geographical area we have 13 rainfall stations at our disposal (not counting the numerous stations available nearby) and seven discharge measurement stations with data covering the period 1951-1992. The regional analysis of rainfall across this catchment area revealed a homogeneous precipitation regime. The rainfall-runoff probabilistic correlation analyses confirmed the relations from the PARDES model and revealed saturation at a return period of 4 years.
\end{abstract}

\section{Introduction}

The aim of this paper is to present a brief review of the application to a specific river basin in Albania of an original probabilistic approach to estimating extreme rainfall events $[1,2]$. This approach forms part of the more comprehensive system named PARDES ${ }^{b}$ for processing mean annual rainfall and discharges as well as daily rainfall and peak flood discharges. This part of the method is an extension of the Gradex method [3].

This approach was calibrated during the early 1990s and has been validated over the past 20 years on about a hundred projects in France [4] and as many in other countries of the world.

We will begin with a brief reminder of the theory providing the basis for the first part of the method (chap. II), before explaining the method used to determine homogeneous precipitation regimes (chap. III). We will then present its application to the Vjosa river basin (chap. IV). Next, we will describe the formulations used and the theoretical elements substantiating the second part of the method (probabilistic rainfall-runoff relations) (chap. V). We will then explain the method used to determine the coefficients involved in probabilistic relations (chap. VI). Lastly, we will present the application to the Vjosa river basin (chap. VII). We will conclude with a summary of the benefits of this method in chapter VIII.

\section{Analysing rainfall}

The PARDES system is used in particular to estimate characteristic peak flood discharges, which are important hydrological data in designing river development schemes. Its first stage consists in determining extreme daily rainfall $\mathrm{Rj}$.

The probabilistic hypothesis underlying this approach is based on the fact that the simple exponential decrease in rainfall observed empirically can be justified theoretically by assuming that rainfall events follow a Poisson process. In addition to enabling the rainfall frequency distributions to be determined, this theory offers a number of other highly useful properties [5]. In this context it can hence be demonstrated that the annual maxima follow a Gumbel distribution with two parameters, one corresponding to the mean rainfall value and the other to the mean number of rainfall events $(v)$. In practice, the fit of the rainfall observed on a Gumbel graph produces a straight line defined by $\mathrm{Y} 0$, the abscissa at the origin of the distribution, and $\mathrm{Rdm}$, the mean value

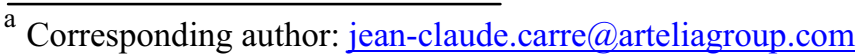

b PARDES is an acronym standing for "Probabilistic Analysis of Rainfall and Discharge for Engineering Studies"
} 
of the annual maximum daily rainfall. Y0 is the Gumbel variable where the Gumbel straight line cuts the axis $\mathrm{Rd}$ $=0$ (fig. 1). The Poisson process theory establishes the relation $v=\exp (-Y 0)$. It should be noted that the smaller the value of $Y 0$, the greater the frequency of such events.

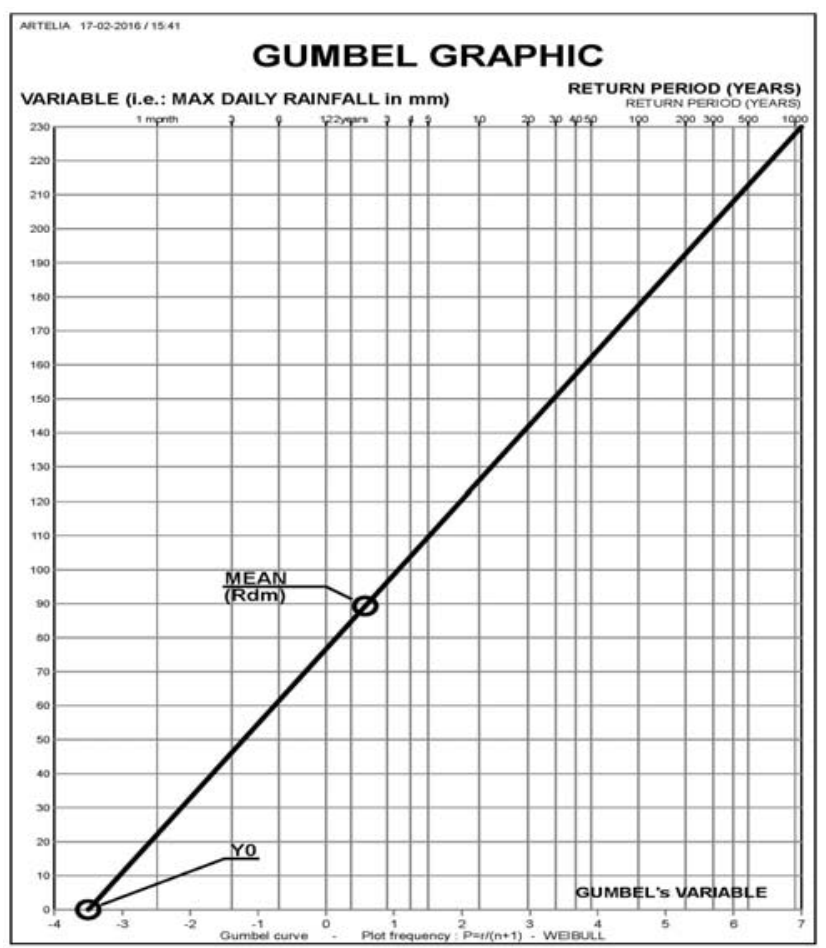

Figure 1. Gumbel graph - distribution with two parameters.

From a physical point of view, rainfall events cross large territories covered by several rainfall stations. The same number of events should hence be found at these stations, meaning in practice that $v$ is a constant for a given area which we will hence call a region and that, for this region, the parameter $\mathrm{Y} 0$ of the Gumbel distribution is also a constant. The rainfall regime is hence described as homogeneous.

This consequence of the theory hence makes it possible to consider a regional approach to set a regional value of Y0. All that then remains is to estimate locally the mean daily rainfall defining the slope of the straight line on the Gumbel graph (Gradex). This method offers a means of significantly reducing the sampling uncertainty on the determination of rainfall in comparison with conventional statistical methods that adjust the statistical laws to the local values from a rain gauge.

However, we have been able to observe [6] that the fits are not always straight and can take the form of a broken line due to threshold phenomena associated with orography or the presence of a cold air mass (Mesoscale Convective System (MCS) or cold air mass trapped against high ground).

Indeed, within a given region the value of $\mathrm{Y} 0$ is unique but the mean varies due to orographic effects: the regression lines form a beam (see illustration on figure 7). For example, rainfall is twice as heavy on a windward mountain slope as in the plain, due to the fact that each weather system is activated (the unstable air mass must rise and cool) on reaching the obstacle formed by the mountain.

However, the more the air mass is unstable the earlier it will be activated, and hence the heavier the rainfall will be. A rain gauge located in the foothills (A on the following graph) will hence receive the rainfall falling in the plain if the weather system is not very active and the rainfall from the mountainside during a major episode. In this case the regime observed will be mixed, combining light plain rainfall and heavy mountain rainfall. The parent population forms an S-shaped curve between two straight lines with the same origin: the "plain" straight line and the "mountain" straight line. We will refer to "breaks" in the fit.

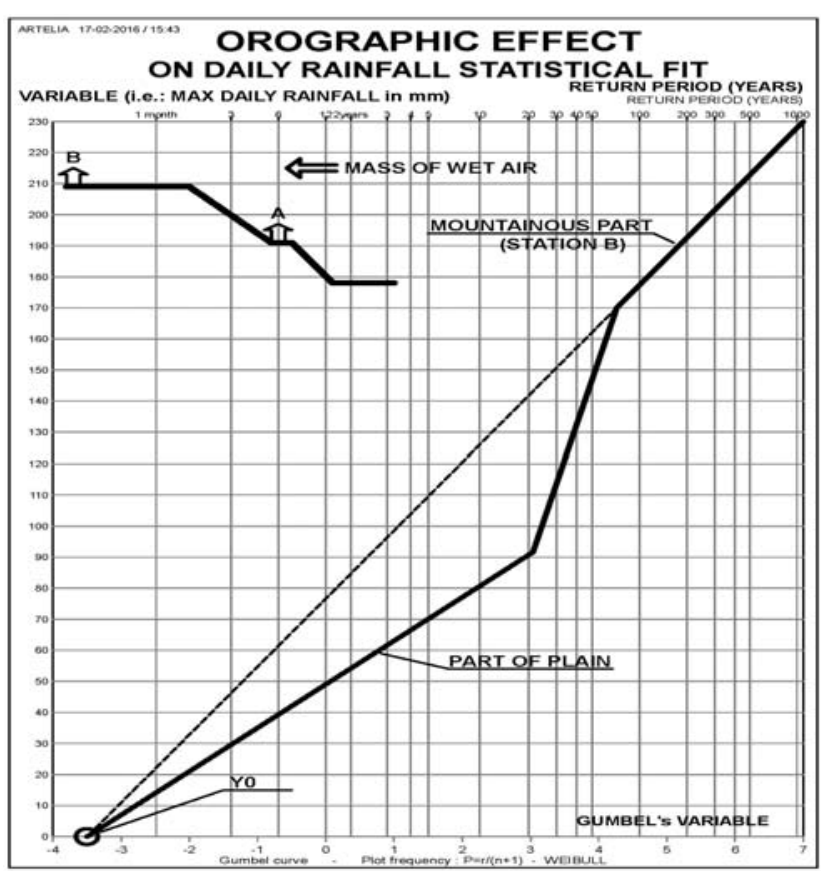

Figure 2. Orographic effect on daily rainfall statistical fit.

If the rain gauge is installed quite a long way from the mountain, only exceptional episodes will be activated at this location: one or two outliers will be observed there. The same applies when the obstacle is a cold air mass stagnating here and there, being recorded randomly at different meteorological stations, or in the case of a MCS.

\section{Determining Y0 and rainfall}

Determining the regional value of the parameter $\mathrm{Y} 0$ involves the following steps:

Series of annual maximum daily rainfall data collected from several rainfall stations are analysed separately in order to obtain local estimations of the mean value of the parameter $\mathrm{Y} 0$ of the Gumbel distribution.

The $80 \%$ confidence interval around this mean local value is then estimated. Next, a graph plotting all of the points and their confidence interval is drawn (see illustration on figure 6). The most probable regional 
value of $\mathrm{Y} 0$ is the one intercepting the largest number of intervals (see example in table 1).

\section{Application to rainfall in the Vjosa river basin}

\subsection{Presentation of the river basin}

The Vjosa River flows through southern Albania. Its length is $272 \mathrm{~km}$, of which $80 \mathrm{~km}$ are in Greece. Its catchment area measures about $6704 \mathrm{~km}^{2}$, of which $4365 \mathrm{~km}^{2}$ are in Albanian territory.

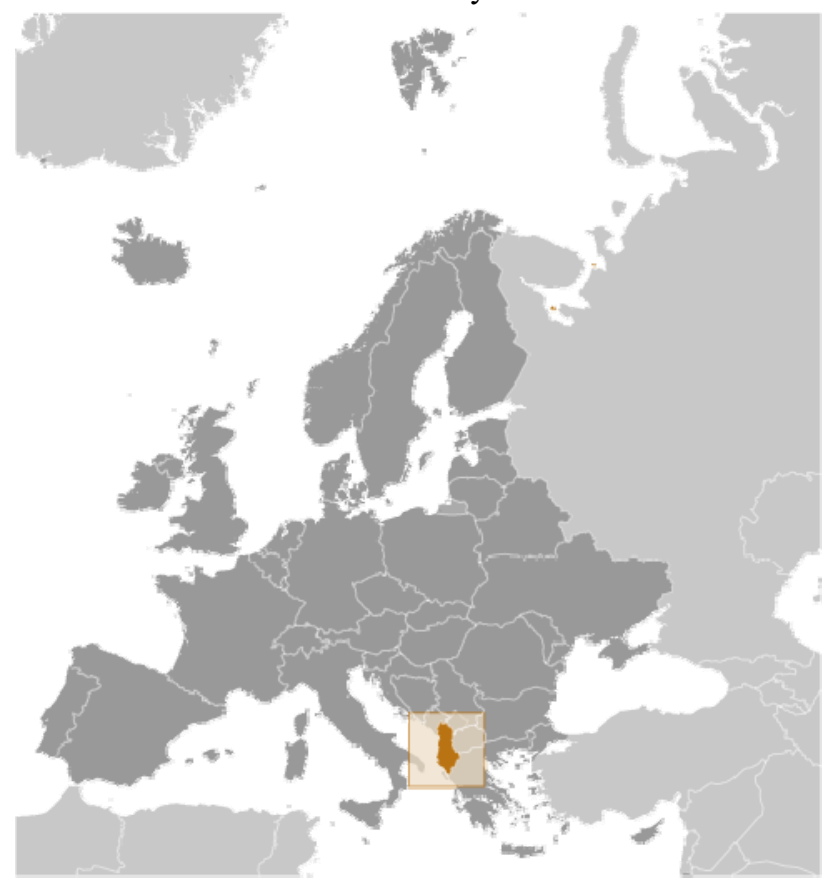

Figure 3. General situation of Albania.

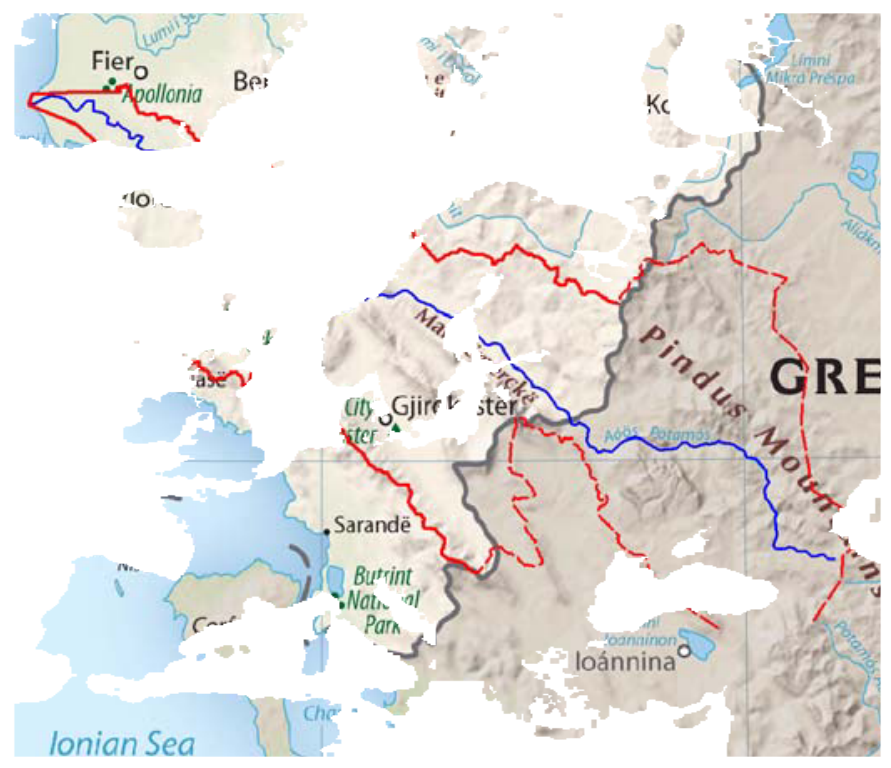

Figure 4. Vjosa river basin.

\subsection{Meteorological stations and YO}

The Vjosa River basin is or has been equipped with several meteorological stations (18). The locations of these stations are shown on figure 5. It should be noted that the quality of the monitoring of the stations has diminished in recent years, with several of the historical stations even being abandoned. The periods of the data series rarely go beyond 2000 and often stop at the beginning of the 1990s. This means that the data analysis is carried out without data from recent years.

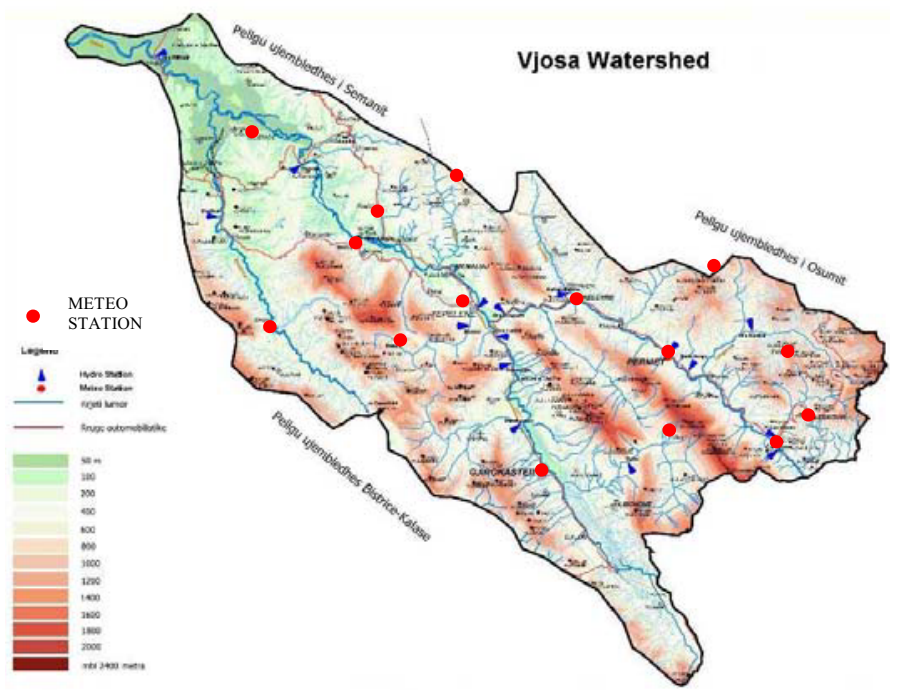

Figure 5. Meteo stations on Vjosa river basin in Albania.

However, the regional analysis is performed on all the available rainfall stations presenting sufficiently long samples and no "breaks" in their fit (approx. 30 stations). The issue of "breaks" will be discussed later in this paper.

We applied the methodology described in chapter 3 to these 30 stations in order to obtain an estimation of the regional value of $\mathrm{Y} 0$. For each station we thus determined the local mean value of the parameter Y0 and calculated the associated $80 \%$ confidence interval.

We then determined the number of ranges intercepted for different Y0 values. Table 1 below shows that the value of -3.1 cuts the largest number of ranges. The graph in figure 6 illustrates this result.

\begin{tabular}{|c|c|c|c|}
\hline Y0 & NB & NB $=$ & NB > \\
\hline-2.5 & 18 & 11 & 1 \\
\hline-2.6 & 15 & 13 & 2 \\
\hline-2.7 & 15 & 13 & 2 \\
\hline-2.8 & 12 & 16 & 2 \\
\hline-2.9 & 10 & 18 & 2 \\
\hline-3.0 & 7 & 21 & 2 \\
\hline-3.1 & 4 & 23 & 3 \\
\hline-3.2 & 4 & 21 & 5 \\
\hline-3.3 & 4 & 20 & 6 \\
\hline-3.4 & 4 & 19 & 7 \\
\hline
\end{tabular}

Table 1. Number of ranges intercepted depending on $\mathrm{Y} 0$ values 


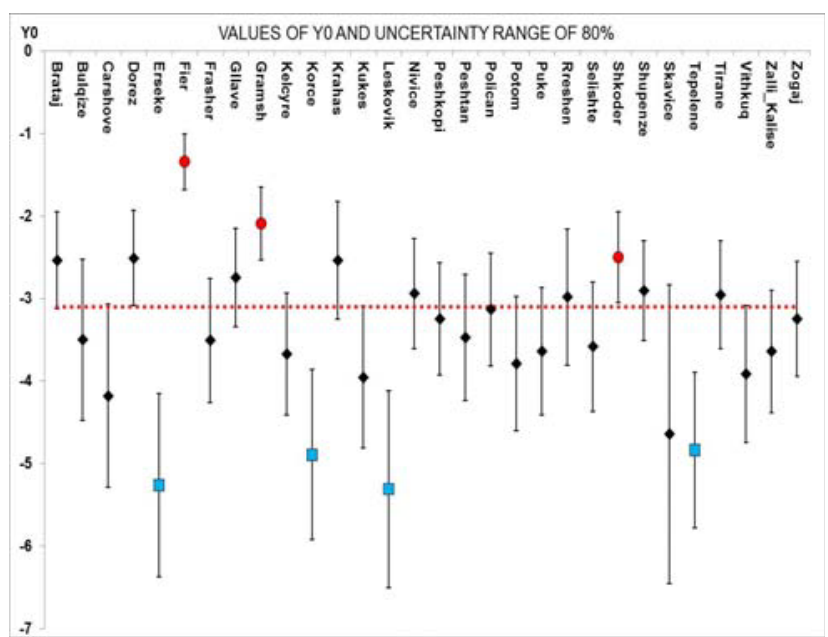

Figure 6. Y0 values and $80 \%$ uncertainty range

\subsection{Rainfall in the basin}

Having determined the parameter Y0, the next task, for each rainfall data series, is to define a fit passing through the point (Y0;0) and the mean, taking a "break" into account if appropriate.

The following graph summarises the 15 data samples analysed concerning the Vjosa river basin.

\begin{tabular}{ccccccccc}
\hline $\begin{array}{c}\text { Raingauge } \\
\text { Station }\end{array}$ & \multicolumn{4}{c}{ Coordinates } & \multicolumn{3}{c}{ Observed Period } \\
& $\begin{array}{c}\text { Latitude } \\
\text { (deg-min) }\end{array}$ & $\begin{array}{c}\text { Longitude } \\
\text { (deg-min) }\end{array}$ & $\begin{array}{c}(\mathbf{m}) \\
\end{array}$ & & From & To & Nb \\
\hline Brataj & 40 & 16 & 19 & 40 & 230 & 1951 & 1991 & 38 \\
Carshove & 40 & 07 & 20 & 32 & 360 & 1971 & 1991 & 28 \\
Dorez & 40 & 23 & 19 & 49 & 370 & 1951 & 1991 & 39 \\
Frasher & 40 & 22 & 20 & 26 & 970 & 1951 & 1992 & 42 \\
Gjirokaster & 40 & 05 & 20 & 08 & 193 & 1951 & 1996 & 46 \\
Gllave & 40 & 30 & 19 & 58 & 875 & 1951 & 1991 & 41 \\
Kelcyre & 40 & 19 & 20 & 12 & 182 & 1951 & 1998 & 48 \\
Krahas & 40 & 27 & 19 & 51 & 500 & 1970 & 1997 & 29 \\
Leskovik & 40 & 09 & 20 & 36 & 920 & 1951 & 1991 & 40 \\
Nivice & 40 & 14 & 19 & 54 & 780 & 1951 & 1990 & 37 \\
Permet & 40 & 14 & 20 & 21 & 240 & 1951 & 1998 & 48 \\
Peshtan & 40 & 15 & 20 & 32 & 700 & 1951 & 1991 & 40 \\
Polican & 40 & 08 & 20 & 21 & 755 & 1951 & 1991 & 41 \\
Selenice & 40 & 32 & 19 & 38 & 100 & 1954 & 1997 & 42 \\
Tepelene & 40 & 18 & 20 & 01 & 220 & 1951 & 1999 & 46 \\
\hline
\end{tabular}

Table 2. List of rain-gauge stations in the Vjosa basin

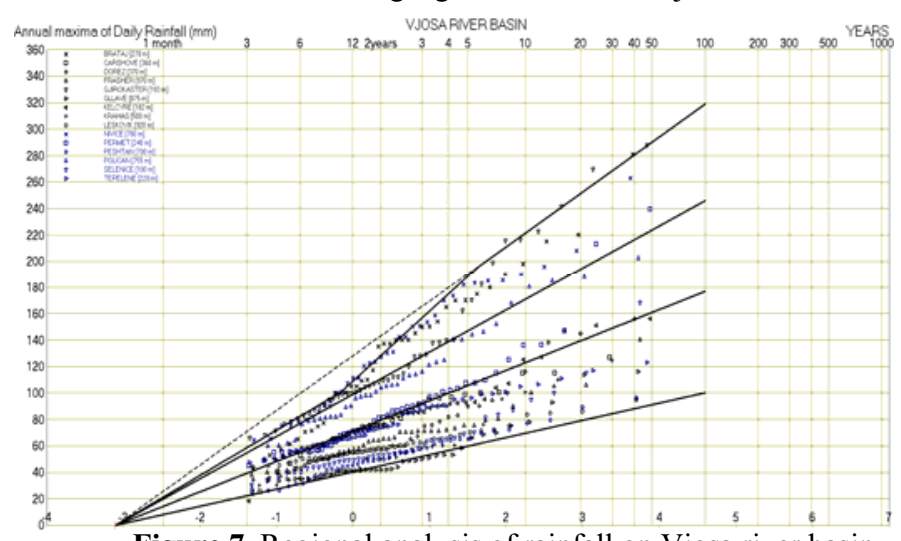

Figure 7. Regional analysis of rainfall on Vjosa river basin

A significant spatial variation in daily rainfall is observed.
The fits from the Polican and Pehtan stations are closely aligned with the Y0 value adopted.

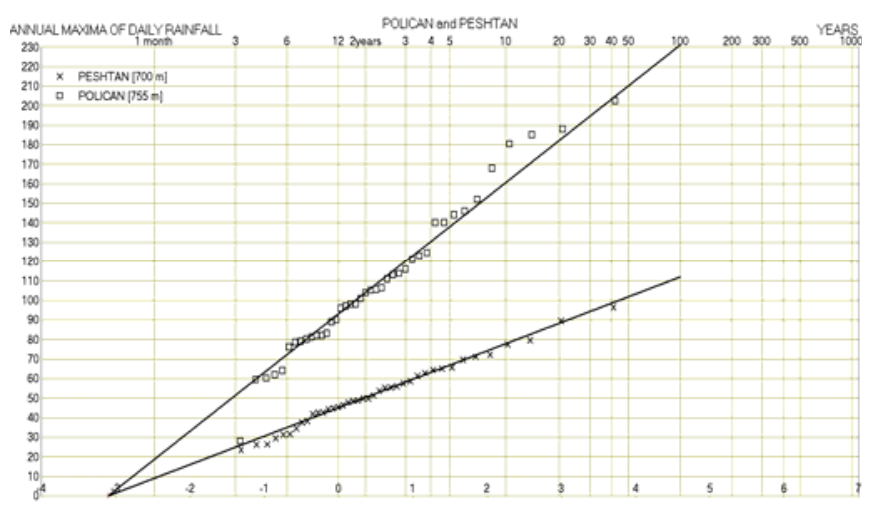

Figure 8. Unique line daily rainfall fits

The Dorez, Krahas and Gjirokaster stations present "breaks".

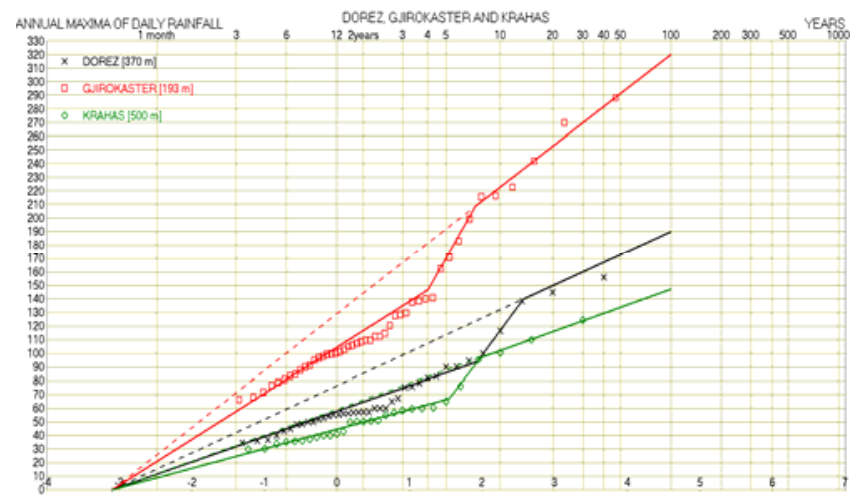

Figure 9. Dorez, Krahas and Gjirokaster daily rainfall fits.

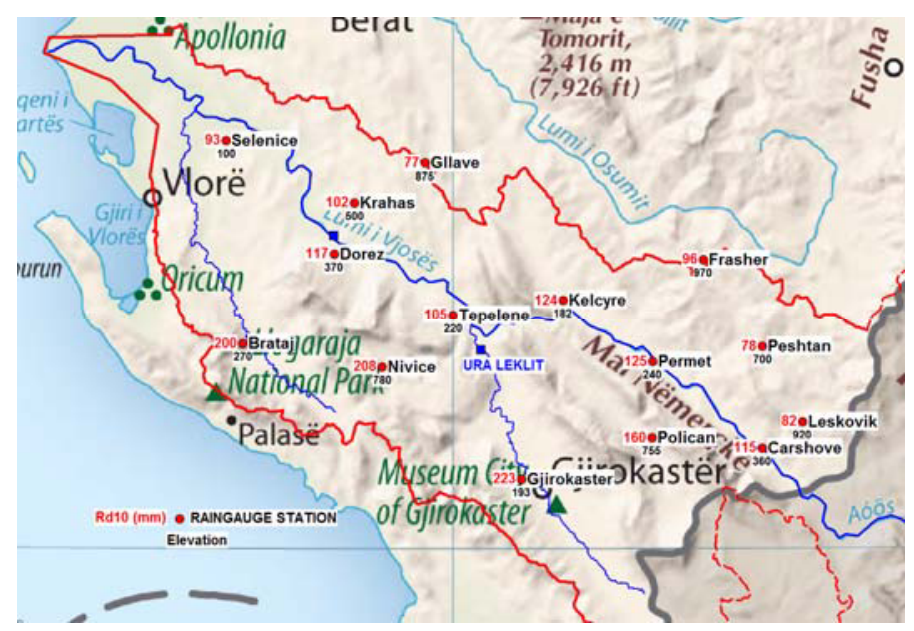

Figure 10. Locations of rain gauges on Vjosa basin, and Rd10 and altitude values.

A general study of rainfall over several river basins in Albania showed that rainfall decreases from north to south and from west to east. On the Vjosa basin, we can see that the possibility of an orographic or atmospheric effect resulting in phenomena associated with rare events not being mitigated has to be taken into account. 


\section{Probabilistic rainfall-runoff correlation}

The PARDES (flood) method is based on the application of two probabilistic relations written as follows:

$$
\begin{gathered}
Q R_{T}=C_{0}\left(R_{T}-R_{0 i}\right) \\
Q R_{T}=R_{\mathrm{T}}-R_{0}
\end{gathered}
$$

Where:

$\mathrm{Q}_{\mathrm{T}}$ : the peak discharge quantile with return period $\mathrm{T}$

$\mathrm{S}$ : the surface area of the river basin (in $\mathrm{km}^{2}$ )

$\mathrm{R}_{\mathrm{T}}$ : the daily rainfall quantile with return period $\mathrm{T}$ (in $\mathrm{mm}$ )

$\mathrm{R}_{0 \mathrm{i}}$ : the initial loss (en mm)

$\mathrm{C}_{0}$ : the empirical coefficient of rainfall-runoff proportionality prior to saturation

$\mathrm{R}_{0}$ : the probabilistic runoff threshold (in $\mathrm{mm}$ )

$\mathrm{T}_{0}$ : the saturation return period (initially set at 10 years in the Gradex method [3])

$\mathrm{QR}_{\mathrm{T}}$ : working variable named reduced discharge (in $\mathrm{mm})$, such that

$$
Q_{T}=Q R_{T} \cdot S^{0.75} / 12
$$

(The coefficient 12 has the dimension of $\mathrm{s} . \mathrm{m}^{-0.5}$ )

It is important to note that these relations connect statistical quantiles and not deterministic values. They hence cannot be applied to the reproduction of specific events. In other words, the parameters $\mathrm{C} 0, \mathrm{R} 0 \mathrm{i}$ and $\mathrm{R} 0$ are random variables whose mean value we are attempting to determine. In hydrology, precipitation and the reaction of a river basin to rain showers depend on so many fluctuating intermediate conditions that the hydrological variables can be deemed purely random.

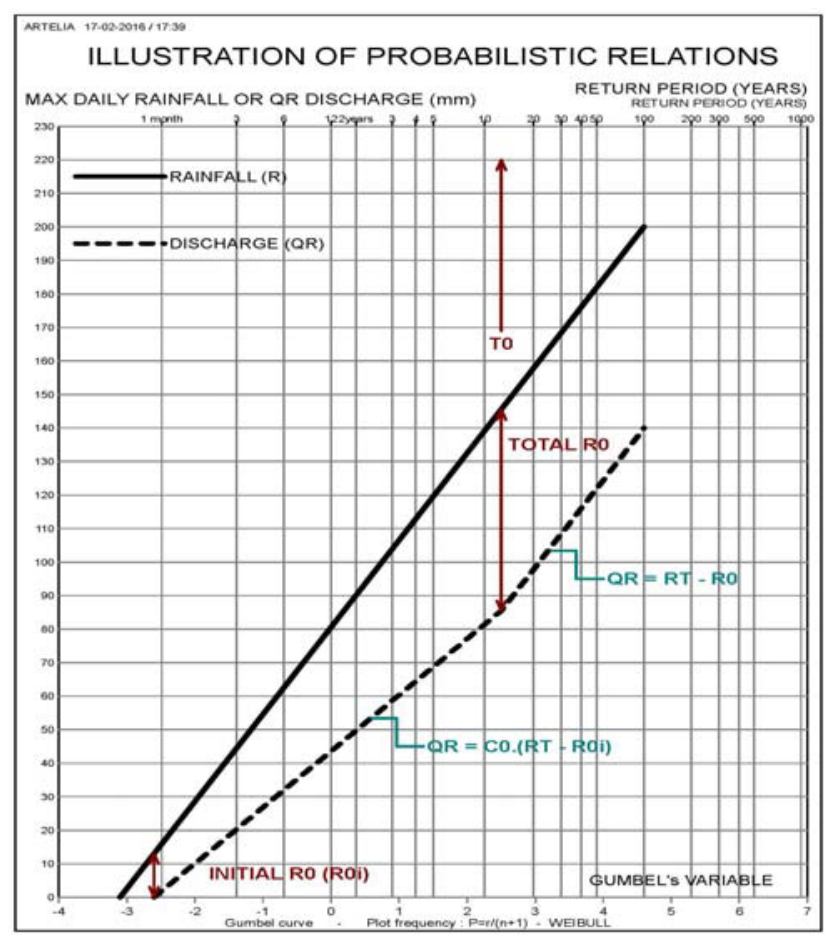

Figure 11. Illustration of probabilistic rainfall-runoff correlation.

\section{Determination of coefficients $\mathrm{CO}$ and Ro}

The determination of coefficients $\mathrm{C} 0$ and $\mathrm{R} 0$ is carried out by establishing the probabilistic equifrequency correlation between reduced discharge and daily rainfall at the rain gauge assumed to represent characteristic rainfall on the river basin. This is done using the following procedure:

- Extract the discharge and rainfall samples over a common period

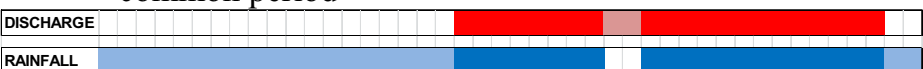

- Sort the extracted data in ascending or descending order

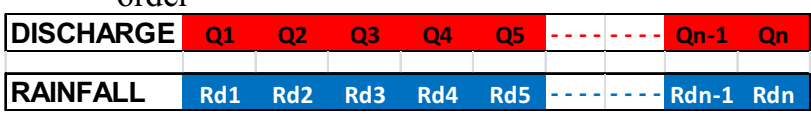

- Plot the graph of the couples $(\mathrm{QR} 1, \mathrm{Rd} 1), \ldots(\mathrm{QRn}$, Rdn)

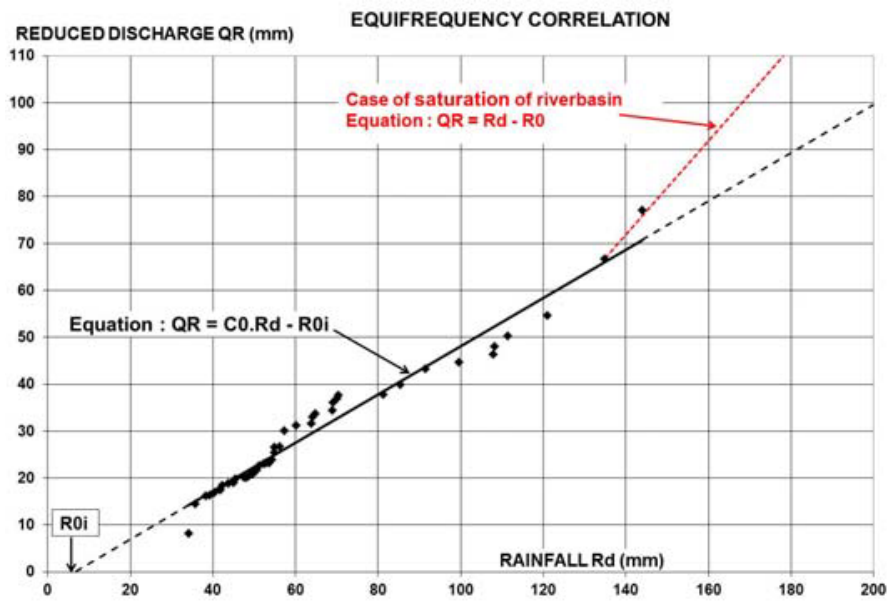

Figure 12. Illustration of equifrequency correlation.

It should be noted that the line does not join the origin point. The R0i value corresponds to the rain that will be absorbed in the soil before any runs off.

The soil is saturated at a certain rainfall value. At this point R0 (mm) is calculated, which corresponds to the total value of rainfall that can be absorbed by the soil. These values (R0i and R0) are statistical mean values; the actual values may differ for each event.

\section{APPLICATION TO THE VJOSA BASIN}

\subsection{Preliminary steps}

In the PARDES approach the first step is to determine a mean catchment rainfall on the basis of the regional rainfall analysis, taking into account the data from the various rainfall stations. This is done using a GIS tool. In the event of a somewhat inhomogeneous rainfall distribution (as is found here), an uncertainty range is derived for the mean catchment rainfall.

The next step is to establish the rainfall-discharge relations of several pairs of one rainfall station and one 
gauging station. The characteristic values $\mathrm{C} 0, \mathrm{R} 0, \mathrm{~T} 0$ of the rainfall-discharge relation are determined for each pair.

For very inhomogeneous catchment areas (which is not the case here), particular care would need to be taken when applying the method, e.g. splitting the area in the analysis.

\subsection{Application 1}

The analysis of the hydrological data from the Vjosa River basin presents one case of saturation. Considering the discharge data at Dorez gauging station $\left(5420 \mathrm{~km}^{2}\right.$ $64.33 \mathrm{~m}$ - data from 1959 to 1989) and the rainfall data measured at Carshove, the following correlation is obtained:

\section{EQUIFREQUENCY CORRELATION}

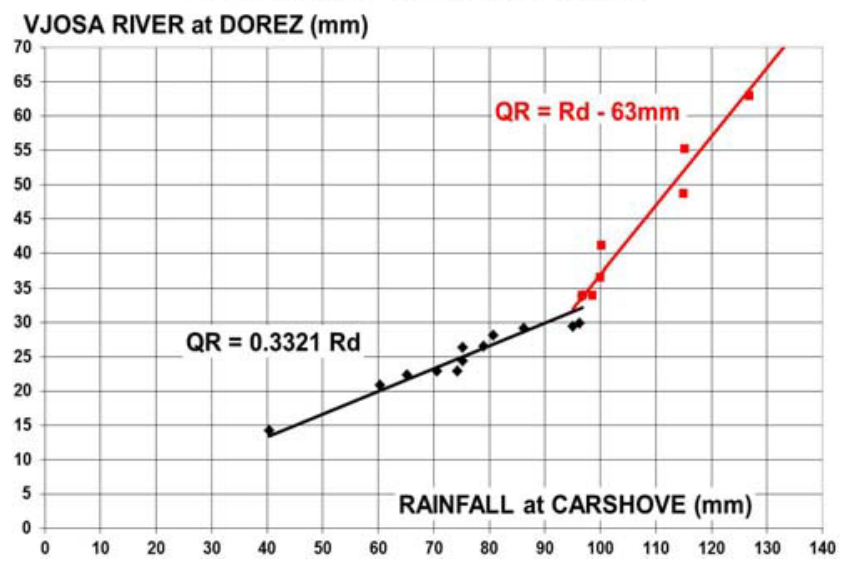

Figure 13. Equifrequency correlation between Dorez reduced discharge and Carshove rainfall

The coefficients are as follows:

- $\mathrm{R} 0 \mathrm{i}=0 \mathrm{~mm}$

- $\mathrm{C} 0=0.3321$

- $\mathrm{R} 0=63 \mathrm{~mm}$

The relations between rain and reduced discharge are:

$$
\begin{array}{ll}
Q R=0.3221 . R d & \text { if } R d<97 \mathrm{~mm} \\
Q R=R d-63 & \text { if } R d>97 \mathrm{~mm}
\end{array}
$$

The relations are established based on the data that were measured over the same period $(1971$ - 1989 i.e. 19 years).

These relations are then applied to the total rainfall data (parent population) measured at Carshove, as shown on the figure hereafter, to which we have carried over data on the common period (in red dots).

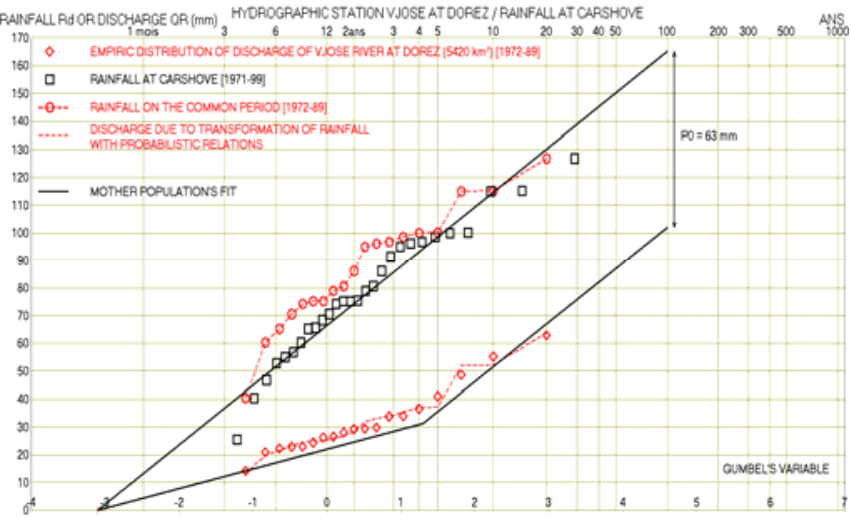

Figure 14. Reduced discharge of Vjosa at Dorez explained by rainfall at Carshove

A comparison of the induced distribution of reduced discharges with the empirical distribution of these discharges over 17 years reveals a difference which can be explained by the fact that rainfall exceeds the characteristic values during this period. T0 (return period associated with saturation) is also seen to amount to 4 years.

\subsection{Application 2}

In some cases the two above-mentioned cases orographic effect and soil saturation - can be observed on the same graph. For example, the results of the correlation of the discharges measured on the Drinos river at Ura Leklit and the rainfall measured at Gjirokaster and Polican are as follows.

The gauging station at Ura Leklit was installed in 1950. 49 years of discharge data were available (until 1999).

The equifrequency correlation with rainfall at Polican covers the period 1951-1991 (40 years). The result is as follows:

\section{EQUIFREQUENCY CORRELATION}

\section{DRINOS RIVER at URA LEKLIT (mm)}

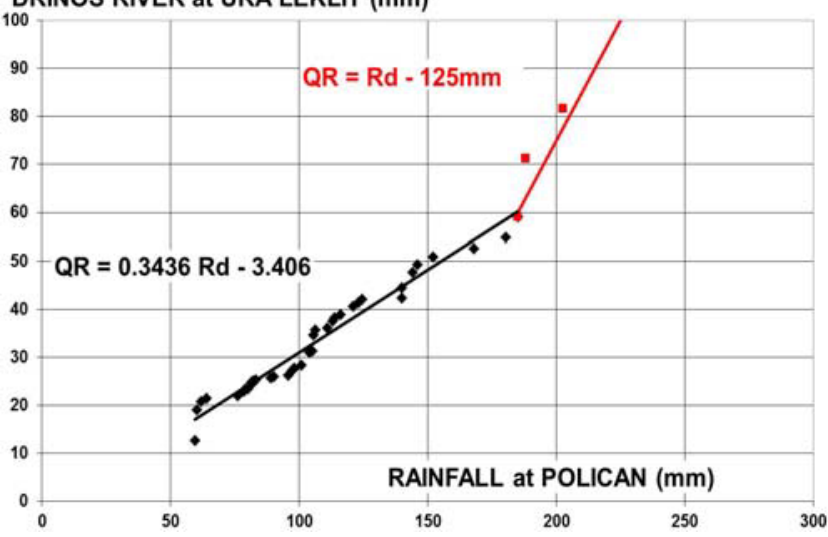

Figure 15. Equifrequency correlation between Drinos river reduced discharge at Ura Leklit and Polican rainfall.

The equifrequency correlation with rainfall at Gjirokaster covers the period 1951-1996 (44 years). The result is as follows: 


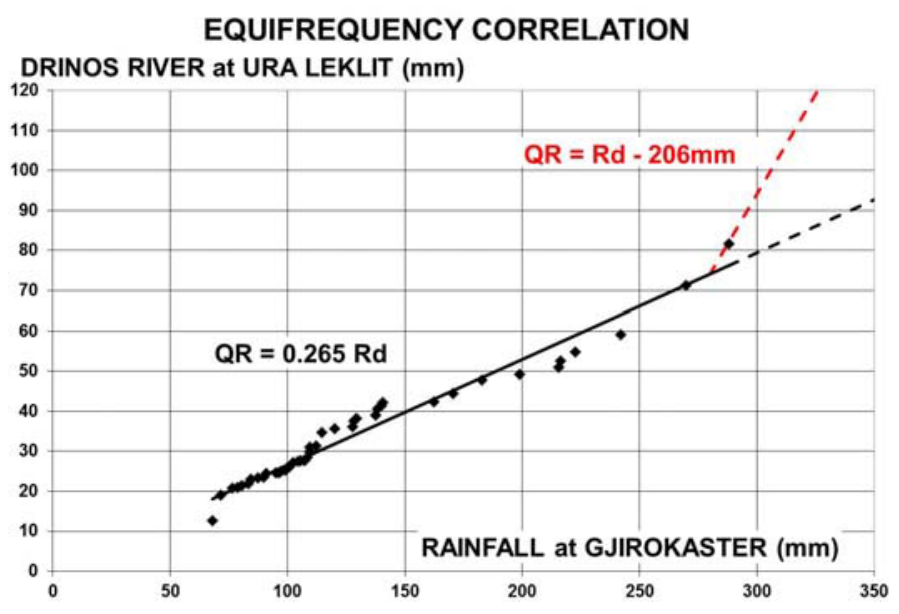

Figure 16. Equifrequency correlation between Drinos river reduced discharge at Ura Leklit and Gjirokaster rainfall.

The figure shows that river basin saturation is not highlighted in a clear manner.

As previously, applying these relations to the total rainfall data produces the following result.

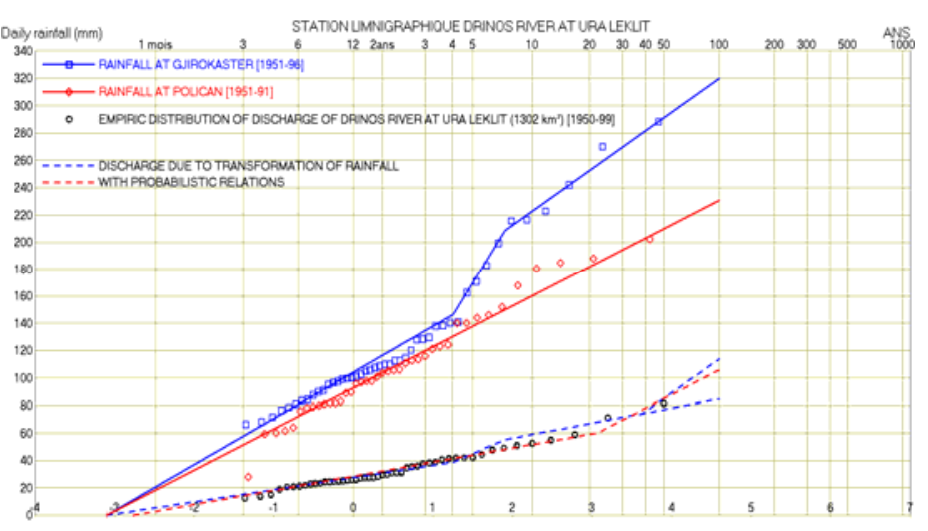

We observe that:

- The orographic effect observed on rainfall at Gjirokaster is reflected on the regression line of the reduced discharges (blue)

- The equifrequency correlation with Gjirokaster rainfall indicates the possibility of river basin saturation; this possibility is confirmed by the equifrequency correlation with Polican rainfall.

\section{Conclusions}

The following points can be noted:

- A regional rainfall analysis offers a means of reducing uncertainty on the rare rainfall values.

- It is capable of revealing any "break" phenomena related to orography or the presence of a cold air mass; such "breaks" make it necessary to re-assess the rare rainfall values.
- Analyses of equifrequency correlation between rainfall and reduced discharges provide a means of transferring the improvement on uncertainty regarding rainfall to discharges.

- The possibilities of river basin saturation can be taken into account more accurately than by simply applying the Gradex theory (saturation for $\mathrm{T}=10$ years).

The studies conducted in this manner in 2009 made it possible to propose discharge values at various potential dam sites with return periods of 1000 years to 10,000 years while reducing uncertainty.

The results obtained provided a means of comparing the different sites.

\section{References}

1. Cayla O. (1993). - Probabilistic calculation of design flood - SPEED. Proc. Int. Symposium on Engineering hydrology - San Francisco, July 25-30 1993, ASCE pp.647-652

2. Cayla O. (1995). - Probabilistic calculation of design floods and Inflows - SPEED; WaterPower 95 ASCE - San Francisco, July 25-28 1995, pp. 24762486

3. CFGB (1994). - Les crues de projet des barrages : méthode du Gradex. Design Flood Determination by the Gradex Method. $18^{\text {eme }}$ congrès CIGB-ICOLD Bulletin du comité français de grands barrages, $\mathbf{n}^{\circ} \mathbf{2}$, November 1994, 7-96.

4. J.C. Carré (2013). Extreme peak discharge evaluation through a probabilistic approach: assessment of 20 years experience by Artelia/Sogreah. Evènements extremes d'inondation, SHF - Lyon, 13-14 November 2013

5. Cayla O. and J.P. Broch, (1992). - Probabilistic regional precipitation analysis. Proc. Hydropower'92, Broch et Lysne (eds), Balkema, Rotterdam, 389-394

6. Cayla O. and J.C. Carré (2012). Regional probabilistic approach of extreme rainfall events in metropolitan France. Evènements extrêmes fluviaux et maritimes, SHF - Paris, 1-2 February 2012 